\title{
Emotional intelligence and empathy: its relevance in the clinical encounter
}

This article was published in the following Dove Press journal:

Patient Intelligence

9 May 2011

Number of times this article has been viewed

\section{Paul Burcher \\ Department of Philosophy, University of Oregon, Oregon Health Sciences University}

\begin{abstract}
The clinical relationship between patient and health care provider is an emotion-laden experience for both participants. Emotional intelligence has an obvious role in medicine on both sides of the clinical relation. This review examines the impact of emotional intelligence from both the patient and physician perspective. On the patient side, emotional intelligence may have a role in both acute and chronic illness, and the possibility of impacting health care utilization and treatment strategies deserve further exploration. For physicians, patient satisfaction and clinical outcomes may be improved by enhancing and valuing physician intelligence and empathy.

Keywords: emotional intelligence, empathy, doctor-patient relationship
\end{abstract}

The clinical encounter, or the relation between physician and patient, is perhaps unique in that the exchange and processing of emotionally laden information must often occur rapidly and between two people who may be near strangers to one another. Because of the "emotional labor" involved in many clinical relationships, ${ }^{1}$ it is not surprising that attempts have been made to understand the correlation between a physician's emotional intelligence and clinical skills and outcomes. The patient's ability to respond to illness, and even her perception of herself as healthy or sick, may similarly depend upon her emotional intelligence.

Emotional intelligence was first defined and developed as a concept two decades ago by Salovey and colleagues. Their understanding of this construct has evolved so that they now define emotional intelligence as:

... the ability to perceive, appraise, and express emotion accurately and adaptively; the ability to understand emotion and emotional knowledge; the ability to access and/or generate feelings when they facilitate cognitive activities and adaptive action; and the ability to regulate emotions in oneself and others. In other words, emotional intelligence refers to the ability to process emotion-laden information competently and to use it to guide cognitive activities like problem solving and to focus energy on required behaviors. ${ }^{2}$

Despite the obvious relevance of emotional intelligence to the medical encounter, the literature relating this concept to medicine is sparse, especially considering the abundant research relating emotional intelligence to success in business and management. ${ }^{3}$ This review will seek to describe and summarize the existing literature on emotional intelligence in medicine, by describing the role of emotional intelligence on both sides of the clinical encounter: that is, from both the patient and physician perspective. 
Empathy is perhaps the most important aspect of emotional intelligence from the physician perspective, so its role will also be examined. ${ }^{4}$

\section{The patient and emotional intelligence}

From the patient side of the clinical dyad, emotional intelligence correlates with a patient's ability to cope with issues of health, suffering, and even mortality. There is evidence that people with low emotional intelligence are more likely to be sick and visit physicians during times of high stress. ${ }^{5}$ Salovey et al proposed that these study subjects may be using the health care system as a way to "regulate" their negative feelings that they were unable to process alone, although their lack of ability to cope with stress may be producing physical symptoms and illness as well. ${ }^{6}$ This has not been confirmed by a follow-up study, so this represents a possible area of further research.

Furthermore, emotional intelligence is not static: it tends to increase with age, and there are numerous studies supporting the ability to teach it and reinforce it, behaviorally. ${ }^{2}$ This suggests that physicians can potentially benefit their patients by teaching components of emotional intelligence that allow patients to recognize stress and respond in healthy adaptive ways. Recent research shows that using exercise and cognitive behavioral therapy significantly reduces symptoms in patients with chronic fatigue syndrome. ${ }^{7}$ This can be interpreted as a specific example where techniques that enhance a patient's understanding of her disease and the nonadaptive thoughts that inhibit recovery, coupled with exercise and stress reduction, have been shown to successfully treat a difficult disorder.

\section{Narrative medicine}

The recent growth and interest in narrative medicine has potential benefits for patient coping as well. Salovey et al cites research showing that inhibition of stress and trauma "burdens and impairs both physical and mental health". ${ }^{6}$ Inhibition here refers to repressing trauma and stress, rather than recounting and working through painful circumstances. Studies have shown that "writing and talking about negative life events", promotes recovery. ${ }^{6}$ Although this is common on the mental health side of healing, it is underutilized and insufficiently appreciated among primary care and, especially, specialist physicians. Techniques of both lengthy clinical encounters with patients that allow them to recount their life stories, and of encouraging patients and physicians alike to journal and at times to share their journal entries with each other, have been developed and popularized by Rita Charon MD; she advocates them in her writings and workshops on narrative medicine as methods of healing in traditional medical settings. ${ }^{8}$

The use of narrative to allow patients to work through trauma and stress can be alternately understood as fostering or increasing patient emotional intelligence by encouraging patients to examine their emotions and better understand their mental and physical responses to them, or as physicians using their emotional intelligence to help others make connections between repressed emotions and physical symptoms. The central point is that patients need and use emotional intelligence to cope with illness, and that at times illness can actually be attributed to gaps in emotional intelligence that physicians may be able to identify and treat narratively or through other psychotherapeutic techniques. Although grappling with patients at this level requires more time in a clinical encounter (and more training in narrativity than most physicians receive), this is still cost-effective medicine compared with ordering expensive tests to "rule out" unlikely diagnoses. Furthermore, the goal of medicine is to heal, or at least reduce suffering. For some ailments, to ignore the impact of stress and a patient's ability to cope with this and other traumas is to miss what may be the only therapeutic option available.

A case example of this clinical approach will be helpful here: a woman with significant vulvodynia - a chronic condition causing pain and burning of the vulva, with an unknown etiology - had not responded well to medical treatment. The physician noticed, after taking care of her for more than a year, that her symptoms seemed to wax and wane with the stresses of her life. When this was pointed out to her, she was initially resistant: she didn't want to accept that there could be a psychosomatic element to her pain; given that vulvodynia is so poorly understood, patients do struggle with the question of whether their pain has a physical cause or not. A few weeks later, she was travelling with her young son, and she lost track of him in a busy airport. She found him after only a few minutes, but losing sight of him was followed by an intense bout of vulvar pain. She returned to the physician's office after this trip, ready to discuss methods of managing her pain that focused on stress reduction, and she subsequently did much better. This patient was intelligent, in the traditional sense, as well as emotionally intelligent, but she still benefitted from having a clinician link her symptoms to her emotional state. Through attention to and insight into her stressors, combined with stress-reduction techniques such as exercise and yoga, the patient was ultimately able to reduce her symptoms. 
The point to be gained from this case is that even emotionally intelligent patients can benefit from a physician who is willing to look for links between illness and emotion. This link is poorly understood; some suffering may arise solely from emotional states and their inhibition or nonrecognition; other diseases such as vulvodynia and chronic fatigue may worsen under stress and respond to therapy that focuses on insight and stress reduction. The physician's emotional intelligence will play a crucial role if we believe that identifying the emotional state of the patient is an important part of the patient's treatment.

\section{The physician and emotional intelligence}

Given the enthusiasm that emotional intelligence has generated in other fields, the paucity of research involving emotional intelligence and physicians is surprising. The studies have been preliminary and largely negative in their findings. There has been only one study addressing the relationship between patient satisfaction and physician emotional intelligence. ${ }^{9}$ The study, by Wagner et al, was small, and most physicians in this academic family medicine department scored highly in emotional intelligence, so the study lacked power to find the difference it was seeking. Despite this, it was found that there was a positive correlation between physician happiness and patient satisfaction $-\mathrm{a}$ finding that is at some level unsurprising, but also suggestive that the patient's emotional intelligence in reading the physician's level of happiness is also in play during a clinical encounter. ${ }^{19}$ Large employers of physicians should perhaps take note regarding this linkage of physician and patient satisfaction if they wish to improve patient approval.

A second study by Azimi et al examined the relationship between the emotional intelligence of dental students and patient satisfaction. ${ }^{10}$ Here there was a significant positive correlation: patient satisfaction was higher when the dental student scored higher on his or her emotional intelligence exam. It is worth noting differences between these two studies to ask why the results are different. The two studies both used the same exam to determine the clinician's emotional intelligence, so this does not confound comparing the two. The study on dental students was larger, and therefore had more power, and the range of emotional intelligences among dental students was also larger, again making the task of discerning a difference easier. But we may also conjecture that the time spent in a typical dental exam significantly exceeds the time spent in a typical medical visit, making the emotional intelligence of the practitioner more obvious to the patient, who has more time to observe the clinician. Given the currently hectic schedules of primary care physicians, it may be difficult to prove any benefit of emotionally intelligent physicians because too little meaningful interaction actually occurs in a typical office visit.

Rather than trying to prove the obvious (that physicians need emotional intelligence to best serve their patients), perhaps we need to focus instead on creating environments and practices that allow emotional intelligence to exert an actual force in the doctor-patient relationship. Thus, as Terry Stratton writes in the discussion of another largely negative study examining the relationship between emotional intelligence and clinical skills, “. . it is only in an organizationally supportive climate that emotional intelligence is translated into emotionally competent behaviors". ${ }^{4}$ Stratton's point is crucial: both medical education and clinical environments are actually antithetical to fostering emotional intelligence in physicians. The long hours of residency training and the increasingly corporate model of employed physicians, who lack control over their schedules and time per visit, could make discussions of emotional intelligence a quaint anachronism, rather than an important determinant of quality of care. Although Carol Elam argues that emotional intelligence may be even more important in the pressure of brief visits, because physicians must be capable of quickly "reading" their patients' emotional states, ${ }^{11}$ it could more convincingly be claimed that the benefits of emotional intelligence are decreased by brief visit times. This is an obvious area of possible future research.

The other reason that it has been hard to establish the benefit of emotionally intelligent care providers may be related to the construct of emotional intelligence itself. Some components, such as a physician's ability to express accurately her own emotions, may be less clinically relevant than other aspects, such as reading the patient's emotional state and expressing empathy. ${ }^{2}$ In fact, the literature on expressions of empathy and care shows a much more positive correlation with patient outcomes than does the literature on emotional intelligence taken as a whole.

\section{The physician and empathy}

As a directly important aspect of the clinical encounter, empathy has numerous studies demonstrating its positive effect on patient outcomes and satisfaction. ${ }^{12}$ It has also been shown to reduce patient anxiety and increase their sense of outcome expectancy, thus enhancing a positive placebo effect. ${ }^{13}$ Furthermore, physicians who see themselves as empathetic are perceived by their patients as being empathetic. ${ }^{14}$ 
One area where an examination of empathy lacks precision over emotional intelligence, however, is that it lacks a consistent, singular definition. ${ }^{15}$ There is general agreement that empathy, in contrast to the closely related term "sympathy", must include a cognitive component. ${ }^{15}$ However, Rebecca Garden and others argue that clinical empathy must also include an action-oriented aspect, or some response that results in material aid to the patient. ${ }^{16,17}$ While I will later address the dangers of empathy, Garden's point is that empathy must result "in an active response rather than an end in itself". ${ }^{16}$ Thinking of empathy as both emotional attunement and as a cognitively processed response is consistent with Salovey's "Four-Branch Model of Emotional Intelligence". Here, empathy is both the ability to identify the emotional states of others, and subsequent problem solving that is facilitated by this identification. ${ }^{2}$

One research tool for measuring empathy in a clinical setting has been the CARE measure (Consultation and Relational Empathy). ${ }^{18}$ The researchers for this measure define empathy as "the ability to communicate an understanding of a patient's world and to act on that understanding in a therapeutic way". ${ }^{19}$ In a large study using this CARE measure in a patient survey, more than three-quarters of the patients responded that empathy was "very important" to them in a clinical encounter. ${ }^{19}$ More surprising is the finding that this response did not vary among patients from differing socioeconomic classes, acute versus chronic illness, gender, or age. That is, regardless of the patient or disease characteristics, a high percentage of patients regard clinical empathy as very important. It seems doubtful that patients are aware of positive outcome data among empathetic physicians, so their desire for empathy in a clinical setting must arise from a different source. The near ubiquitous desire for empathy in the doctor-patient relationship speaks to the nature of illness and the character of the medical encounter.

The philosopher Paul Ricoeur, writing near the end of his life, described the ethical origins of the clinical relationships as beginning in patient suffering..$^{20}$ Beginning in patient need, or lack, a care-giving relationship is founded on mutual trust. He describes this in terms of the differing responsibilities that patient and physician have in the relationship. The patient "brings to language" her suffering, and the physician "follow(s)".${ }^{20}$ This "following" is solicitude, ${ }^{21}$ being open to the uneven reciprocity of a healing relationship: the patient speaks, the doctor seeks to understand the other as best she can, and together a therapeutic plan is formed. Ricoeur describes how in illness we are separated from others, and the medical relationship begins the process of healing by ending this sense of separation. This places empathy at the center of the doctor-patient relationship, because it is precisely the expression of empathy, and the move to end the sense of isolation and suffering that the patient feels, which commences the clinical relationship. Howard Brody describes the doctor-patient relationship itself as a "mode of healing". ${ }^{22}$ This has been obvious to generations of physicians and patients alike, who have known that the physician might have little to offer besides empathy, and remaining with the patient through the illness, regardless of its outcome. I suspect it needs to be restated now, only because the overwhelming optimism engendered by medical technological advances has obscured the insight that a physician's first responsibility is to the patient and to the care-giving relationship. If $75 \%$ of patients see empathy as highly important in the clinical encounter, it appears that patients, at least, have not forgotten this.

\section{Empathy as a problem}

Many of the authors writing on the importance of empathy in the clinical relationship also recognize the potential pitfalls of too much empathy, or the wrong types of empathy. There are several ways in which empathy can become problematic or detrimental to a therapeutic relationship.

1. Overwhelming the clinician: too much identification with a patient can make clinicians susceptible to "affective merging" which can lead to poor clinical decisionmaking from a lack of objectivity. ${ }^{23}$ According to Larson and Yao, the cumulative effect of this may contribute to physician burnout. ${ }^{1}$ As Halpern has argued, empathy requires striking a balance between too detached concern and merging of self and other. ${ }^{23}$ This is akin to Ricoeur's description of the "just distance" - a spatial metaphor for finding the right balance in each encounter that allows a patient to feel the care of the physician, without violation of boundaries or the loss of clinical objectivity. ${ }^{20,24}$

2. Too little cognitive component: empathy can degenerate into sympathy, a visceral response, rather than an emotion-led cognitive response. ${ }^{15}$ Patients should never be placed in a situation where they feel that the physician needs to be comforted, because the physician feels the plight of the patient too deeply. Physicians must be emotionally attuned to their patients, but emotions cannot be the driver of the physician response. As in David Hume's view of the relationship between emotion and reason, emotions can motivate, but reason should still be in charge of decision-making. ${ }^{15,25}$ 
3. Counter-transference: when the patient's pain awakens memories of a similar pain or suffering in the physician, counter-transference may occur, where the physician becomes lost in her own memories or feelings or such loss is made present again by the story of the patient. This can shift the clinician's focus from the patient's suffering, to her own experience of personal suffering, and the patient can in essence be lost. ${ }^{15}$ Davis points out that counter-transference can be harnessed to increase empathy, when done consciously and deliberately. Physicians can look for similarities in their story and the patient's story, as a way of sharing, but they must also be careful to not awaken personal emotions that may then take the center stage away from the patient. As Halpern describes it, clinical empathy must remain patient-centered, and not devolve into a physician being lost in her own emotions, which were elicited by the patient encounter. ${ }^{23}$ Although "resonating" with a patient can be part of an empathic response, physicians must learn to keep this in check, without negating the reaction entirely.

\section{Empathy as emotional attunement}

Halpern gives the most complete description of how physicians can be empathetic, while avoiding these pitfalls. She describes clinical empathy as "emotional attunement," an emotional awareness that seeks for clues of the patient's emotional state from nonverbal signals. ${ }^{23}$ It is neither "detached concern", nor immersion in patients' emotional states to the point of actually feeling what they feel. Rather it involves "imagin[ing] what the patient is going through", after sensing the emotions the patient has conveyed through subtle cues and body language. This sensitivity may or may not engender resonance with the patient's feelings. But even if it does not, the physician is then more apt to respond appropriately to the patient, because she is responding to both the words and emotions conveyed by the patient. Halpern sees empathy as central to good clinical medicine, and argues that this attunement must be taught to doctors in training, and reinforced at an institutional level, by giving physicians enough time with patients, and insisting upon reasonable work hours.

\section{Conclusion}

The clinical encounter, as a care-giving relationship, involves both intellect, understood narrowly, and emotional intellect for both sides of the therapeutic dyad. For physicians, both emotional intelligence and empathy are crucial.

Patient emotional intelligence deserves further study, although it is already clear that low emotional intelligence is associated with greater illness and health care utilization, and that efforts to augment emotional intelligence may be of benefit, particularly in chronic disease. Screening for emotional intelligence could someday become a part of health care evaluation, and even cost containment, because it appears to play a role in both the development and treatment of illness.

Physician emotional intelligence may contribute to better outcomes and patient satisfaction, although further research may establish this relationship more completely. It may be of greater research interest to arrive at a consistent definition of empathy, and continue to investigate its role in outcomes and patient satisfaction, because it appears that empathy may be the most important component of emotional intelligence in the health care setting.

Emotional intelligence and empathy can be understood as being both innate and learned. That is, education, age, and gender all impact their development, but some people more easily acquire these abilities than others. Given the importance, even centrality, of empathy to the doctor-patient relationship, testing for empathy in medical student applications seems entirely reasonable. Furthermore, every effort needs to be made to eliminate the aspects of medical education that are dehumanizing and contribute to a loss of empathy among physicians. Work hour restrictions, courses in medical humanities and narrative medicine, and training in psychosocial medicine all have the potential to improve empathy among new physicians. Continuing Medical Education (CME) credits in these same areas may benefit existing physicians.

\section{Disclosure}

The author reports no conflict of interest in this work.

\section{References}

1. Larson E, Yao X. Clinical empathy as emotional labor in the patientphysician relationship. JAMA. 2005;293(9):1100-1106.

2. Salovey P, Mayor JD, Caruso D. The positive psychology of emotional intelligence. In: Synder CR, Lopez SJ, editors. Handbook of Positive Psychology. New York: Oxford University Press; 2002.

3. Freshman B, Rubino L. Emotional intelligence: a core competency for health care administrators. Health Care Manag (Frederick). 2002;20(4): $1-9$

4. Stratton T, Elam C, Murphy-Spencer A, Quinlivan S. Emotional intelligence and clinical skills: preliminary results from a comprehensive clinical performance examination. Acad Med. 2005;80(10):S34-S37.

5. Goldman S, Kraemer D, Salovey P. Beliefs about mood moderate the relationship of stress to illness and symptom reporting. J Psychosom Res. 1996;41:115-128.

6. Salovey P, Bedell BT, Detweiler JB, Mayer JD. Coping intelligently: emotional intelligence and the coping process. In: Synder CR, editor. Coping: The Psychology of What Works. New York: Oxford University Press; 1999:141-164. 
7. White $\mathrm{P}$, Goldsmith K. Comparison of adaptive pacing therapy, cognitive behavior therapy, graded exercise therapy, and specialist medical care for chronic fatigue syndrome (PACE): a randomised trial. Lancet. 2011;377(9768):823-836.

8. Charon R. Narrative Medicine: Honoring the Stories of Illness. New York: Oxford University Press; 2006.

9. Wagner P, Moseley M, Grant M, Gore J, Owens C. Physicians' emotional intelligence and patient satisfaction. Fam Med. 2002;34(10):750-754.

10. Azimi S, Farid AAA, Fard K, Khoei N. Emotional intelligence of dental students and patient satisfaction. Eur J Dental Educ. 2010;14: 129-132.

11. Elam C. Use of "emotional intelligence" as one measure of medical student applicants' noncognitive characteristics. Acad Med. 2000;75(5): 445-446.

12. Hoja M. Empathy in Patient Care: Antecedents, Development, Measurement, and Outcomes. New York: Springer; 2007.

13. Verheul W, Sanders A, Bensing J. The effects of physicians affectoriented communication style and raising expectations on analogue patients' anxiety, affect and expectancies. Patient Educ Couns. 2010;80: 300-306.

14. Glaser K, Markham F, Adler H, McManus R, Hojat M. Relationships between scores on the jefferson scale of physician empathy, patient perceptions of physician empathy, and humanistic approaches to patient care: a validity study. Med Sci Monit. 2007;13(7):291-294.

15. Davis M. A perspective on cultivating clinical empathy. Complement Ther Clin Pract. 2009;15:76-79.
16. Garden R. Expanding clinical empathy: an activist perspective. J Gen Intern Med. 2008;24(1):122-125.

17. Benbasset J, Baumal R. What is empathy and how can it be promoted during clincal clerkships? Acad Med. 2004;79:832-839.

18. Mercer S, Watt G, Maxwell M, Heaney D. The development and preliminary validation of the consultation and relational empathy (CARE) measure: an empathy-based consultation process measure. Fam Pract. 2004;21(6):669-705.

19. Mercer S, McConnahie A, Maxwell M, Heaney D, Watt G. Relevance and practical use of the consultation and relational empathy (CARE) measure in general practice. Fam Pract. 2005;22: 328-334.

20. Ricoeur P. Decision making in medical and judicial judgments. In: Pellauer D, trans. Reflections on the Just. Chicago: Univ Chicago Press; 2007.

21. Ricoeur P. Oneself as Another. Chicago: Univ Chicago Press; 1992.

22. Brody H. Medicine's continuing quest for an excuse to avoid relationships with patients. Am J Bioethics. 2009;9(12):13-15.

23. Halpern J. What is clinical empathy? J Gen Intern Med. 2003; 18(8):670-674

24. Qualtere-Burcher P. The just distance: narrative, singularity, and relationality as the source of a new biomedical principle. J Clin Ethics. 2009;20(4):299-309.

25. Hume D. A Treatise on Human Nature. New York: MacMillan and Co; 1888.
Patient Intelligence

\section{Publish your work in this journal}

Patient Intelligence is an international, peer-reviewed, open access journal that characterizes and measures the central role of patient behavior and intention in optimizing healthcare management in all areas of disease and complaint types. An improved understanding of patient intelligence coupled with predictive analysis helps an organization contribute more effectively to achieving better outcomes.

Submit your manuscript here: http://www.dovepress.com/patient-intelligence-journal

\section{Dovepress}

The journal is characterized by the rapid reporting of reviews, original research, methodologies, analytics, modeling, clinical studies and patient surveys across all disease areas. The manuscript management system is completely online and includes a very quick and fair peer-review system. Visit http://www.dovepress.com/ testimonials.php to read real quotes from published authors. 